\title{
Regularization of a half-center oscillator network by closed-loop control
}

\author{
Irene Elices ${ }^{*}$, Pablo Varona \\ From 24th Annual Computational Neuroscience Meeting: CNS*2015 \\ Prague, Czech Republic. 18-23 July 2015
}

Central Pattern Generators (CPGs) are neural circuits that control muscle functioning by means of rhythmic patterns. These networks are usually built up on a minimal configuration based on reciprocal inhibitory connections responsible for the production of alternating spiking-bursting activity. Experimental observations in the crustacean pyloric CPG show that most neurons, when isolated, present a highly irregular, in fact chaotic, bursting activity [1-3]. This rich intrinsic dynamics provides flexibility for negotiating rhythms through the reciprocal inhibitory connections between neurons which lead to the regularization of the chaotic behavior when the neurons interact within the circuit [4].

Closed-loop interactions are typically used in electrophysiological experiments using dynamic clamp protocols [5] and have been generalized for different description levels of the nervous system [6]. In this work we show that feedback protocols can also be used in theoretical studies to search for specific dynamics or explore the parameter space of a given model. We have built a CPG model based on a minimal network with two neurons connected by bidirectional fast chemical inhibitory synapses. The network generates alternating bursting activity in the neurons, which can be regular or irregular depending on the maximal conductances of the inhibitory synapses. We employ a simple adaptive closed-loop protocol to regularize the alternating chaotic activity of the model (see Figure 1 panel A). This protocol adapts online the maximal conductance of one of the synapsis to achieve the aimed regular alternating bursting activity (see Figure 1, panel B). Moreover, the closed-loop algorithm can be used to automatically map the region of maximal conductance values that lead to regular activity.

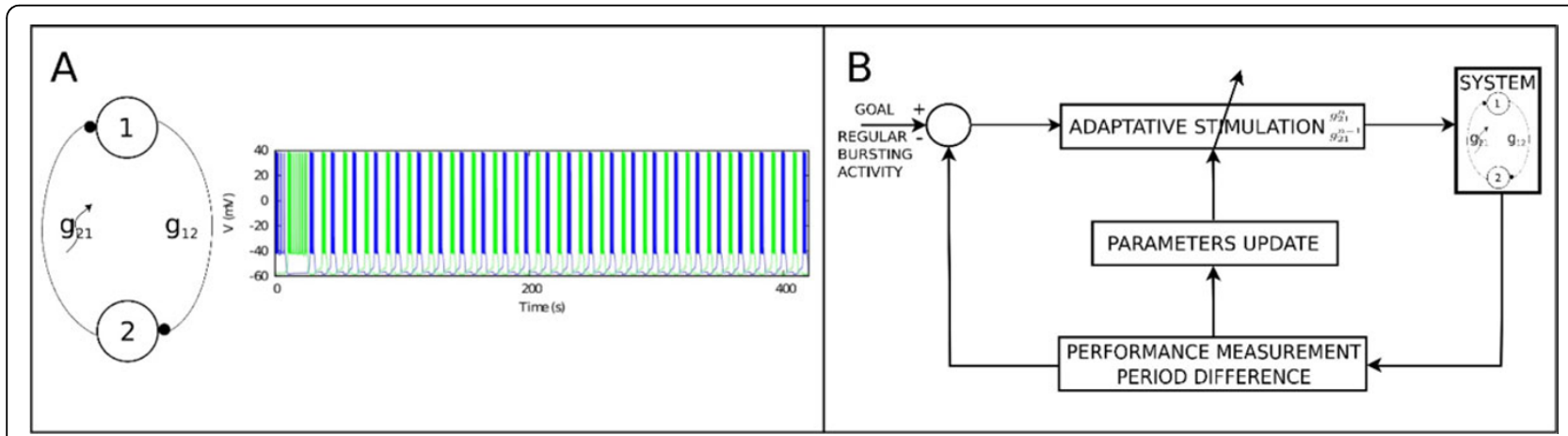

Figure 1 Panel A: Activity of the system using the closed-loop algorithm. Panel B: Schematic representation of the closed-loop protocol.

\footnotetext{
* Correspondence: irenelices@uam.es

Grupo de Neurocomputación Biológica, Departamento de Ingeniería

Informática, Escuela Politécnica Superior, Universidad Autónoma de Madrid,

Madrid, 28049, Spain
} 


\section{Acknowledgements}

Authors acknowledge support by MINECO TIN2012-30883 and ONRG grant N62909-14-1-N279.

Published: 18 December 2015

\section{References}

1. Abarbanel HD, Huerta R, Rabinovich Ml, Rulkov NF, Rowa PF, Selverston Al: Synchronized action of synaptically coupled chaotic model neurons. Neural Comput 1996, 8(8):1567-1602.

2. Elson RC, Huerta R, Abarbanel HD, Rabinovich MI, Selverston Al: Dynamic control of irregular bursting in an identified neuron of an oscillatory circuit. J Neurophysiol 1999, 82(1):115-122.

3. Varona P, Torres JJ, Abarbanel HD, Rabinovich MI, Elson RC: Dynamics of two electrically coupled chaotic neurons: experimental observations and model analysis. Biological Cybernetics 2001, 84(2):91-101.

4. Selverston Al, Rabinovich Ml, Abarbanel HD, Elson R, Szücs A, Pinto RD, Huerta R, Varona P: Reliable circuits from irregular neurons: a dynamical approach to understanding central pattern generators. J Physiology-Paris 2000, 94(5):357-374.

5. Destexhe A, Bal T (Eds): Dynamic-Clamp: From Principles to Applications Springer, New York; 2009.

6. Chamorro P, Muñiz C, Levi R, Arroyo D, Rodríguez FB, Varona P: Generalization of the dynamic clamp concept in neurophysiology and behavior. PLoS One 2012, 7:e40887.

doi:10.1186/1471-2202-16-S1-P275

Cite this article as: Elices and Varona: Regularization of a half-center oscillator network by closed-loop control. BMC Neuroscience 201516 (Suppl 1):P275.

\section{Submit your next manuscript to BioMed Central and take full advantage of:}

- Convenient online submission

- Thorough peer review

- No space constraints or color figure charges

- Immediate publication on acceptance

- Inclusion in PubMed, CAS, Scopus and Google Scholar

- Research which is freely available for redistribution

Submit your manuscript at www.biomedcentral.com/submit 